\title{
El color de la nación argentina. Conflictos y negociaciones por la definición de un ethnos nacional, de la crisis al Bicentenario
}

\author{
por Ezequiel Adamovsky
}

Abstract. - This article analyses the emergence of a non-diasporic "negro" identity in Argentina in the past three decades, as a reaction against discrimination of the poor on "racial" grounds. Although this discrimination is not new, the narrative of the white-European nation sponsored by the State made it almost impossible to confront it, or at least not openly. However, the weakening of the Nation-state as the aftermath of economic and political crisis opened up a new space for renegotiating the definition of the Argentinean ethnos. By examining different manifestations of lower class culture - from the spread of afro-Brazilian religions to murgas in carnival, and from popular music to political appeals - this article explores the ethnic dimension to class identities in recent Argentinean history. The emerging "negro" identity is interpreted as a metonymic mark in a class identity, rather than an ethnic identity properly speaking.

Las élites que construyeron la nación argentina lo hicieron postulando que ella se encarnaba en un pueblo blanco-europeo. A fines del siglo XIX los habitantes de origen amerindio y africano fueron declarados extintos o reconocidos como un residuo del pasado ya sin peso y en vías de desaparición, por efecto del enorme torrente inmigratorio europeo. Las narrativas que dieron consistencia a una identidad nacional se construyeron, de ese modo, alrededor de la idea de que el "crisol de razas" había dado como resultado una "raza argentina" que era perfectamente blanca y de origen europeo. En su funcionamiento práctico, el mito del crisol de razas no excluía de la pertenencia a la nación a las personas de otros colores de piel o extracciones étnicas. Más bien, las forzaba a "disimular" cualquier marca de su origen diverso, como condición para participar como ciudadano en la vida nacional. Un permanente "patrullaje" cultural funcionó desde entonces para borrar cualquier presencia que pudiera refutar o amenazar la consisten- 
cia de esa Argentina blanca-europea. Tal patrullaje no estuvo sólo en manos del Estado: mediante la intimidación, las burlas, o incluso la violencia, también los habitantes comunes participaron en él. ${ }^{1}$ Su efectividad, sin embargo, dependía de la capacidad del Estado-nación de sostener una promesa de integración a la vida social disponible para todos.

A pesar de la inestabilidad que caracterizó a la Argentina del siglo XX, hasta mediados de la década de 1970 el Estado consiguió ir ampliando los sentidos de la ciudadanía y los derechos asociados a ella, al tiempo que el desempeño económico garantizó importantes canales de ascenso social y niveles de desigualdad (comparativamente) no muy pronunciados. Durante esas décadas, algunos discursos públicos procedentes de ámbitos políticos e intelectuales intentaron impugnar la narrativa construida en torno del "crisol de razas", al tiempo que la cultura de masas incluyó alusiones (más bien indirectas) a la diversidad étnica de la nación. Existieron también algunas pocas estrategias plebeyas de visibilización de lo no-blanco. Sin embargo, ni unas ni otras consiguieron socavar el dominio de los discursos oficiales de la nación, que siguieron girando en torno de un Pueblo ideal homogéneo e "incoloro" (es decir, implícitamente blanco). Para las clases populares, el horizonte de ampliación del bienestar estuvo asociado al aprovechamiento de las oportunidades que ofrecía el mercado y de los canales que habilitaba la política estatal. Sus identidades primarias se expresaron en términos de clase y rara vez pusieron en cuestión la pertenencia a ese Pueblo homogéneo al que apelaban tanto el Estado como las principales ideologías políticas.

Las cosas comenzaron a cambiar en ese sentido a partir de 1976. El golpe militar de ese año inauguró un largo período de clausura política, seguido de regímenes democráticos que sólo ofrecían formas de participación devaluadas, de baja intensidad y escasa capacidad de incidir en las decisiones fundamentales. Las políticas neoliberales implementadas desde entonces empobrecieron notoriamente a la población, particularmente en sus estratos más bajos. Las funciones de bienestar del Estado fueron rápidamente desmanteladas, al tiempo que altas tasas de desempleo y una nueva legislación "flexibilizadora", impulsada especialmente en los años noventa, acababan con buena parte de los derechos laborales y, con ellos, con la capacidad de presión de las organizaciones sindicales. El resultado fue una catástrofe socioeconómica, patente en el empeoramiento de todos los indicadores de desarrollo y bienestar sociales, que alcanzó su pico máximo inmediatamente después de la crisis de 2001, la peor en toda la historia argentina. En ese contexto de alta fragmentación, el "patrullaje cultural"

1 La noción de "patrullaje" está tomada de Rita Segato, La nación y sus otros (Buenos Aires 2007), p. 30. 
que aseguraba la consistencia de un Pueblo homogéneo perdió parte de su efectividad, abriendo la oportunidad para cuestionamientos más abiertos y profundos. A ello también contribuyó el impacto de discursos multiculturalistas a nivel internacional, que alcanzaron influencia en los medios de comunicación y en la alta política argentina en los años noventa.

\section{Nuevas identidades emergentes}

La cultura popular expresó de diversas maneras los cambios de la época. El debilitamiento de la presencia integradora del Estado y el fin de la "sociedad salarial" - es decir, del empleo como columna vertebral de los proyectos de vida de las personas - generaron toda una serie de efectos culturales novedosos. La ciudadanía había perdido en parte su sentido real y concreto y eso abría para muchos una crisis del sentido de pertenencia a una comunidad nacional. El contacto con el trabajo era más fragmentado y efímero, lo que significaba que las identidades trabajadoras que habían vertebrado el mundo popular también entraban en crisis. La crisis de los sentidos de pertenencia abrió la posibilidad de que cada cual buscase nuevas maneras de sentirse parte de alguna comunidad, sea acercándose a una nueva, sea intentando hacer lugar para comunidades más pequeñas y particulares dentro de la nación. Las identidades populares se volvieron así menos generales y homogeneizantes y más fragmentadas, particulares y efímeras. Con la nación como espacio de referencia compitieron ahora identidades más locales y otras más "globalizadas", promovidas especialmente por los medios de comunicación. ${ }^{2}$

Parte de estas renegociaciones de los sentidos de pertenencia apuntaron directamente al sentido de la "argentinidad". De varias formas las clases populares impugnaron en estos años, con más fuerza que nunca, las definiciones de lo argentino propuestas por la cultura dominante. El área donde esta novedad se notó con mayor fuerza fue la de la etnicidad. Entre los pueblos originarios, los años ochenta y noventa presenciaron un resurgir del interés de los más jóvenes por el legado de sus mayores, acompañado de una intensa actividad de afirmación de la cultura propia. Algunas de sus organizaciones incluso se atrevieron a rechazar públicamente cualquier pertenencia a la nación argentina, origen de sus desgracias. Este entusiasmo, combinado con la oportunidad de obtener beneficios exclusivamente reser-

2 Para los cambios en la cultura popular, véase Pablo Alabarces/María Graciela Rodríguez (eds.), Resistencias y mediaciones (Buenos Aires 2008); Daniel Míguez/Pablo Semán (eds.), Entre santos, cumbias y piquetes (Buenos Aires 2006). 
vados a indígenas de parte del Estado o de ONGs, motivó en estos años incluso el renacimiento de etnias que se creían extintas. ${ }^{3}$

Pero así como hubo procesos de "reetnización", también hubo otros de "desetnización". Para muchos, el mejor modo de restaurar un sentido de pertenencia ante una nación que no les hacía lugar no fue afirmarse en el legado étnico, sino más bien dejarlo de lado para abrazar una religión alternativa. En efecto, el pentecostalismo y otras religiones protestantes tuvieron un veloz crecimiento en comunidades de varios pueblos originarios: la fuga de la religión oficial - el catolicismo - era también un escape de la oficialidad de una nación que no parecía tener lugar para ellos. Por el contrario, adherir al culto evangélico les permitía reconstruir los lazos comunitarios sobre bases nuevas, más allá de la nación y de las fronteras, escapando del estigma de ser "indios" y a la vez reclamando para sí la superioridad de pertenecer a la religión "verdadera". ${ }^{4}$

Así como el debilitamiento de la presencia integradora del Estado, el fin de la "sociedad salarial" y las dudas sobre el sentido de la ciudadanía abrieron un espacio para la mayor visibilidad de los pueblos originarios, lo mismo sucedió con los no-argentinos. La presencia de inmigrantes de países limítrofes dentro de las clases populares no era una novedad, pero sólo a partir de la década del ochenta fueron ganando mayor visibilidad y reclamando el derecho de mantener abiertamente una cultura propia y diferente (en parte, como reacción a nuevas formas de xenofobia oficial que se hicieron presentes durante la dictadura militar y posteriormente). ${ }^{5}$ La expansión y visibilidad de la cultura de las diversas colectividades de países limítrofes, sin embargo, no se restringió a las personas del mismo origen ni a un interés puramente nacional. Con frecuencia expresó también una afirmación más genérica de lo indo-afro-latinoamericano, cuyos productos - en especial la música - encontraron resonancia entre algunos argentinos de clases populares, aquellos que buscaban, acaso inconscientemente, una reformulación del significado de lo nacional.

\section{Los complejos sentidos de lo negro}

En este contexto, me interesa analizar la emergencia de identidades "negras" y los sentidos múltiples que adoptaron. Como parte de los proce-

3 Véase Gaston Gordillo/Silvia Hirsch (eds.), Movilizaciones indigenas e identidades en disputa en la Argentina (Buenos Aires 2010), pp. 15-38.

4 Segato, La Nación y sus otros (nota 1), pp. 222-223.

5 Alejandro Grimson, "Relatos de la diferencia y la igualdad: los bolivianos en Buenos Aires": Nueva Sociedad 147 (1997), pp. 96-107. 
sos de reetnización reseñados, desde finales de la década de 1980 se percibió un renacimiento del asociacionismo entre los afroargentinos. La recuperación de una voz y una identidad propias, la valorización del aporte cultural africano a la Argentina, la reconexión con un sentido diaspórico y la denuncia del racismo fueron patrones generales de este impulso. Como ha mostrado Marta Maffia para el caso de los inmigrantes caboverdianos, los jóvenes de la colectividad -buena parte de ellos ya tercera generación de argentinos - se lanzaron en estos años a redescubrir su "negritud" y su vinculación con lo africano, aspectos que las generaciones anteriores habían buscado más bien invisibilizar. ${ }^{6}$

Pero no me interesa en este trabajo ocuparme de la minoría de los afroargentinos, sino de los complejos sentidos de "lo negro" que en estos años se hicieron presentes de manera mucho más masiva entre quienes no tenían ningún motivo para sospechar que fueran afrodescendientes o descendientes de cualquier otro grupo étnico particular. En efecto, con creciente intensidad a partir de fines de los años ochenta se percibe entre las clases populares y sectores medios-bajos un interés por resaltar la negritud como parte de la propia identidad y/o la voluntad de asociarse de alguna manera a lo negro. Más aún, en los años noventa y con más fuerza en la primera década del nuevo milenio, aparecieron por primera vez síntomas de que lo negro - tradicionalmente un insulto o motivo de vergüenza - se transformaba en un emblema de desafiante orgullo.

Los canales por los que lo negro se abrió camino en la nación blanca fueron diversos, incluso inesperados, como la expansión de las religiones de origen afro-brasileño, la más conocida de las cuales fue la umbanda. La primera casa de santo legal comenzó a funcionar en 1966 en el Gran Buenos Aires, pero por entonces permaneció como una rareza. Para 1983 había ya unos cien templos operando legalmente y dos años más tarde el número se había duplicado (la cantidad de los que no se habían registrado era mucho mayor, llegando quizás a los 3000). Cada templo podía tener unos cien adeptos, que se reclutaban entre sectores medios-bajos y clases populares. La propia difusión de la umbanda constituyó un cuestionamiento al mito de la nación blanca, por la hermandad espiritual que planteaba con África y con Brasil. Pero eso no era todo. Además de comunicarse con espíritus que podían ser negros y mestizos, muchos pais y participantes del culto, de piel perfectamente blanca, manifestaron sentirse negros. Como le dijo uno de ellos a una investigadora: "Aquí en Argentina mataron la raíz. Es necesario

6 Marta Maffia, "Migración, identidad y diáspora de caboverdeanos y sus descendientes en Argentina", ponencia en International Conference on Cape Verdean Migration and Diaspora, Lisbon, 6-8 April, 2005. 
ir a buscarla donde aún exista, donde ella está fuerte. Es en Brasil donde nosotros vamos a buscar esa raíz, porque allá aún la tienen."” Tal voluntad de restaurar un legado perdido no impugnaba la argentinidad, pero expresaba la necesidad de volver a discutir sus límites en un sentido más pluralista, que incluyera lo negro, en lugar de excluirlo o invisibilizarlo. El carácter plebeyo y subversivo de la umbanda la hizo demasiado indigerible. A partir de 1990 recibió ataques de la Iglesia católica y de los medios de comunicación, bajo acusaciones falsas de practicar sacrificios humanos.

El interés por lo negro se hizo visible también en la aparición, durante la década del ' 90 , de iniciativas culturales orientadas a la recuperación del candombe, a la enseñanza de bailes africanos, o a la difusión de estilos de percusión afro-uruguayos. ${ }^{8}$ Como Alicia Martín ha señalado, el progresivo renacimiento de las murgas de carnaval en Buenos Aires a partir de 1983 incluyó interesantes ejercicios identitarios por los que varias de ellas construyeron linajes presentándose como herederas de murgas de tiempos pasados en las que familias de afroporteños, supuestamente, habrían dejado su impronta. La evocación de tal pasado servía para canalizar un vago posicionamiento político en el presente: funcionaba a la vez como marca del carácter plebeyo de la murga, asociada a los sufrimientos de los pobres, pero también como promesa de un futuro sin pesares. La siguiente estrofa, registrada por Martín en una presentación de los Atrevidos por Costumbre, murga del barrio de Palermo, es un buen ejemplo:

\footnotetext{
"Toda la gente parecen negros

que carbonean su piel danzando

y al futuro van llamando

con la nostalgia de algún tambor."9
}

Por otra parte, aunque "negro" siguió utilizándose insistentemente como insulto en el mundo futbolero, aparecieron también allí algunas reivindicaciones positivas, como en la bandera " $100 \%$ negro botellero y bostero" que utilizaron hinchas del club Maipú de Mendoza.

Pero la reivindicación de lo negro se hizo particularmente evidente y mucho más masiva en la música popular. En verdad, el tango y los candombes de los años cuarenta, o la música folklórica en los años sesenta y setenta, abundaron en composiciones que recordaban la presencia de lo negro como

7 Segato, La Nación y sus otros (nota 1), p. 249.

8 Véase Alejandro Frigerio, "Usos de África en un país 'blanco': Reivindicando la tradición y la identidad negra en Buenos Aires", ponencia inédita, XXIV Encontro Anual da ANPOCS, Petrópolis (Brasil), 23-27 de Octubre de 2000. Facilitada por el autor.

9 Alicia Martín, "Tradicionalizaciones en las memorias de afrodescendientes en los carnavales porteños": El Corsito 38 (2010), s./p. 
parte de la nación. Pero en los años noventa las evocaciones alcanzaron mayor difusión y un tono más militante. En ningún ritmo se notó tanto como en la cumbia - un género de raíces africanas e indígenas procedente de Colombia -, que en los años ochenta cautivó a la mayor parte de las clases populares de todo el país y experimentó un notorio florecimiento comercial. La propia expansión de un ritmo tan poco europeo o "nacional" como la cumbia puede interpretarse como signo de una vocación de participar en una expresión que unificaba a las clases populares de buena parte de América Latina. Pero eso no fue todo. Como parte de esta "movida tropical", hacia finales de la década del noventa, un grupo de artistas jóvenes, algunos de ellos de orígenes muy modestos como Pablo Lescano, desarrollaron un estilo nuevo. Retomando algunos elementos del gangsta rap que venía haciendo furor en los Estados Unidos, compusieron cumbias con letras que referían a episodios a la vida cotidiana de los sectores más marginales, a la violencia, las drogas, la vida carcelaria y la represión. De la escena hip hop también tomaron algunos fraseos y el gusto por la ropa deportiva. Consiguieron así el apoyo de un empresario discográfico que desde entonces comercializó su música con el nombre de "cumbia villera". Otros siguieron su ejemplo y el subgénero pronto alcanzó una enorme difusión. Sus canciones se afirmaban en un orgullo plebeyo que disparaba de manera explícita contra los prejuicios sociales, con críticas a la discriminación, contra los "chetos" y los ricos, la policía y los políticos corruptos. La estigmatización del pobre como "negro" motivó en algunos de estos artistas, desde fines de la década de 1990, una respuesta que convertía el estigma en emblema de orgullo. ${ }^{10}$ El grupo Meta Guacha lo expresó así en una canción de 2002:

"Tu tienes la piel más clara

Paseas en auto por la ciudad.

Yo vivo en un barrio pobre, donde se aguanta a mate y pan.

No sé quién te dio derecho para decirme negro del plan:

ya sabes que a este negro

donde tu quieras lo podés probar."11

${ }^{10}$ Véase Eloísa Martín, "La cumbia villera y el fin de la cultura del trabajo en la Argentina de los 90": Revista Transcultural de Música 12 (2008). Disp. en http://www.sibetrans. com/trans/a90/la-cumbia-villera-y-el-fin-de-la-cultura-del-trabajo-en-la-argentina-de-los-90\# _ednref1 [acc. 9/10/2011].

${ }^{11}$ Meta Guacha, "Negro del plan", del disco Ollas Vacías (2002). 
La glorificación de la violencia y la vida "descontrolada" de algunos de los conjuntos de cumbia villera generaron intensos debates públicos hasta que finalmente, en 2001, el Estado emitió una resolución prohibiendo su difusión en medios de comunicación, bajo la acusación de hacer apología de la droga y el delito. Muy pronto el subgénero decayó. Pero varios de los artistas que lo impulsaron se las arreglaron para mantenerse en carrera, suavizando sus letras. El interés por lo negro no desapareció: Pablo Lescano, que hoy tiene una enorme popularidad, lleva tatuada en el pecho una frase de orgullo repetida por todas partes en la movida tropical: " $100 \%$ negro cumbiero". Hasta el día de hoy arenga a su público en los recitales gritándoles "Las palmas de todos los negros jarriba!", a lo que sus seguidores responden con gran entusiasmo. Una letra de 2007 del grupo El Empuje planteó la cuestión como un antagonismo de clase (chetos vs. pibes del barrio) y a la vez de los colores:

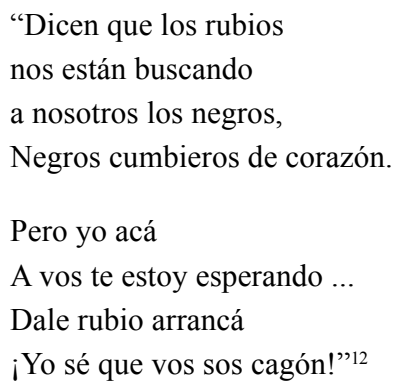

A la manera de Lescano, una canción de 2009 de El Dipy - que desarrolló su carrera solista luego de disolverse El Empuje - arenga a su público gritando: "Si sos negro cabeza ¡Bien arriba esa cerveza!"13 Uno de los mayores éxitos del 2010, la canción "Negro cumbiero donde voy" de McCaco, ${ }^{14}$ también participó del clima de afirmación de lo negro, que por lo demás se reflejó intensamente en los nombres de nuevas bandas, blogs y páginas web $y$ en los comentarios de los fans cumbieros. ${ }^{15}$

Rastros similares de apropiación positiva de lo negro se encuentran en la música de cuartetos, la preferida de las clases populares cordobesas. Por ejemplo la Mona Jiménez - astro máximo del género - hizo un elogio a la "piel de mi raza, raza negra" en su disco Raza Negra (1994), que vendió

${ }^{12}$ El Empuje, "Nos están buscando", del disco Estamos Más Allá (2007).

${ }^{13}$ El Dipy, "100\% cumbiero", del disco No me fui (2009).

${ }^{14}$ Difundida a través de la web, p. ej. en http://www.youtube.com/watch?v=CMckc_ R-228 [acc. 9/10/2011].

15 Por ej. el grupo Caritas Negras, el sitio www.cumbiadenegros.net/, el blog http:// negrocumbiero14.blogspot.com/, etc. [acc. 9/10/2011]. 
10.000 copias sólo en el primer día de su lanzamiento. Además de las letras que lo mostraban de manera explícita, el acercamiento a lo negro en ese disco también se notó en la adopción de arreglos de percusión afro-latina inéditos para la tradición del cuarteto. ${ }^{16}$ En 2000, cuando tuvo la ocasión de dar un recital en el estadio de River Plate, se dirigió a la vez alegre y desafiante al público porteño, gritando: "¡Soy un cabecita negra tocando en River!" ${ }^{17}$ Sus letras en los años siguientes abundaron en críticas a la discriminación y reivindicaciones de lo negro. ${ }^{18} \mathrm{Al}$ menos una porción de los jóvenes seguidores de la música de cuartetos, especialmente los fans de $\mathrm{La}$ Mona, retomó la identidad de "negro cuartetero" (o "negro cabeza") con orgullo y en oposición a los "rubiecitos" (aunque, para otra porción, los "negros cuarteteros" siguen siendo objeto de desprecio). Incluso grupos de jóvenes mujeres se afirmaron como "negras cuarteteras" declarándose culpables, de manera explícita, del delito que les imputa el discurso hegemónico tanto como el del propio público de la movida: el de ser unas "negras putas". ${ }^{19}$

Acaso en sintonía con su origen socialmente más "respetable", el mundo del rock trató menos y más tardíamente el tema de las diferencias en el color de la piel. Aunque la vocación latinoamericana se hizo sentir tempranamente en la adopción de ritmos y estilos de ese origen, en los años noventa hubo en el rock muy pocas recuperaciones de lo negro (aunque fue sintomática la vena autocrítica que apareció en una letra de 1991 del grupo Divididos: "Nace un hijo negro/Cachetazo al rock"). Una excepción fue la banda de thrash metal Malón, cuyo interés por el mestizaje no se evidenciaba sólo en su nombre, sino en letras como "Malón mestizo", de su álbum debut de 1995, que se identificaba con "la negrada cansada y hambrienta" de los alrededores pobres de la ciudad, herederos de los malones aborígenes de antaño. La evocación del pasado, sin embargo, apunta a un futuro de unidad e igualdad:

"Hoy somos miles los que le cantamos

a este rito de igualdad

conciencia firme que aplasta los deseos

de dividir para explotar." 20

${ }^{16}$ Carlos Jimenez: "Raza Negra", del disco Raza Negra (1994).

${ }^{17}$ Clarín, Suplemento Sí, 18/2/2000.

${ }_{18}$ Por ej. "Por portación de rostro", del disco Trilogía 2do. Acto (2006); "No te preocupes", del disco Trilogía 3er Acto (2007).

${ }^{19}$ Gustavo Blázquez, "Negros de alma: Raza y procesos de subjetivación juveniles en torno a los bailes de cuarteto": Estudios en Antropología Social 1:1 (2008), pp. 6-34.

${ }^{20}$ Malón: "Malón mestizo", del disco Espíritu Combativo (1995). 
Poco antes, el popular grupo de rock barrial La Renga había grabado una canción - que también concluye con un vago anuncio de una próxima igualdad - en la que la evocación de la opresión de un esclavo africano opera una transformación en el color de piel del narrador:

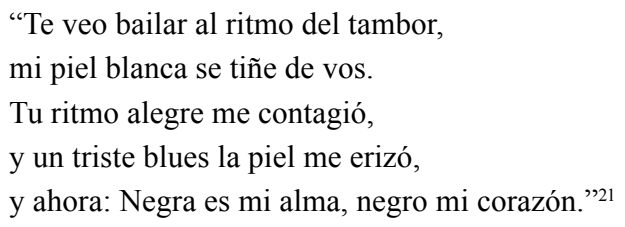

En la primera década del nuevo milenio hubo más voces en el mismo sentido, aunque en general en grupos menos masivos. Por ejemplo, en el Gran Buenos Aires el Culebrón Timbal le cantó al "negro de barrio" y a la "identidad mestiza" mientras que los rosarinos Patagonia ReVelde grabaron su "Chacarera de los Cabecitas Negras" identificándose como tales, algo similar a lo que hicieron en Catamarca los metaleros Arkham con su tema "Cabecita negra", en el que también reclamaban: "Queremos ser parte de nuestra bandera." ${ }^{22}$ El popular Pity Alvarez, por su parte, grabó en 2006 el tema cuartetero "Por portación de rostro" junto a La Mona Jiménez, que refería explícitamente a las diferencias en el color de la piel. ${ }^{23}$ Los seguidores de este género también hicieron propia la cuestión. Desde fines de la década del "90 el cántico "Somos los negros/ somos los grasas/ pero conchetos no" se volvió frecuente entre el público de algunas bandas de rock, como Malón o La Renga. ${ }^{24}$ Sin embargo, también persiste el uso de "negro" en sentido peyorativo, para marcar una distancia respecto del público cumbiero. $^{25}$

Aunque no sea este el lugar para extenderse al respecto, en la literatura argentina reciente también surgieron autores que reclaman para sus personajes un orgullo plebeyo y negro, o buscan situar lo no-blanco como parte

${ }^{21}$ La Renga: "Negra es mi alma, Negro es mi corazón”, del disco Esquivando Charcos (1991).

${ }^{22}$ Divididos en "Haciendo cola para nacer", del disco Acariciando lo áspero (1991); Culebrón Timbal en sus discos 2163 (2003) y El cuenco de las ciudades mestizas (2008); el tema de Patagonia ReVelde incluido en Humo del tiempo (2005); la canción de Arkham en Poder metalero (s./f.).

23 "Por portación de rostro", del disco de Carlos Jiménez Trilogía 2do. Acto (2006).

${ }^{24}$ Véase http://edant.clarin.com/diario/2000/10/16/c-00601.htm; www.youtube.com/ watch?v=nHqR6viRKhE\&feature=related [acc. 9/10/2011].

${ }^{25}$ José Garriga Zucal, "Ni 'chetos' ni 'negros': roqueros": Revista Transcultural de Música 12 (2008). Disp. en http://www.sibetrans.com/trans/a89/ni-chetos-ni-negros-roqueros [acc. 9/10/2011]. 
de la nación. ${ }^{26}$ En las artes plásticas también se perciben intereses similares $^{27}$ y lo mismo vale para el ensayismo y el periodismo. ${ }^{28}$ Cabe destacar que todas estas afirmaciones de lo negro se dan en un marco en el que las agresiones racistas siguen siendo extraordinariamente virulentas, como puede comprobarse con sólo mirar los comentarios que acompañan los videos de grupos cumbieros en Youtube. Un ejemplo entre cientos, en el que se percibe el modo en que lo negro es visualizado como amenaza a la integridad de la nación (blanca):

"Es una mierda esto y la cumbia tambien!! no pueden degenerar mas nuestra cultura argentina mangas de negros giles de mierda!! habria que exterminarlos a todos y este seria una pais mejor, mas limpio, y sin tantos chorros y drogadictos que escuchen cumbia :) ${ }^{\prime 29}$

Lo curioso de esta asunción de lo negro como marca identitaria es que parece ser totalmente independiente de la pertenencia a algún grupo étnico e incluso de los rasgos fenotípicos. Ni los devotos de la umbanda, ni los participantes de las murgas, ni el público cumbiero o cuartetero, son necesariamente afrodescendientes o mestizos, ni tampoco tienen inevitablemente pieles oscuras. Ni Pablo Lescano, ni El Dipy, ni Pity Alvarez, ni la mayoría de los miembros de las otras bandas, son de tez amarronada; la Mona Jiménez es el único de un fenotipo que evoca inmediatamente un linaje afro (aunque él asegura que sólo tiene ancestros europeos y amerindios). ${ }^{30}$

A diferencia de otros países, como Brasil o EEUU, la identidad "negra" que viene emergiendo en las últimas décadas en Argentina no aparece primariamente como santo y seña de un grupo étnico particular, o de un con-

${ }^{26}$ Por ejemplo los libros de Washington Cucurto o algunas novelas históricas; véase Juan Bertazza, "Coronados de tinta": Página 12, 18/7/2010, pp. 25-26. La notable autobiografía de María Irma Ortellado, Huellas de una cabecita negra (Mar del Plata 2009), puede incluirse en este interés.

${ }^{27}$ El ejemplo más claro es el de Daniel Santoro; véase su "La cuestión racial: El peronismo como cosa de negros y la leyenda del descamisado gigante", disp. en www.danielsan toro.com.ar/mundoperonista.php?menu=mundo\&mp=7 [acc. 22/2/2011].

${ }^{28}$ Véase p. ej. Alfredo Arias, La Argentina mestiza (Rosario 2007); Luciana Peker, "Yo soy morocha": Página 12, 5/8/2005; Alberto González Toro, "Ocultamiento de lo oscuro": $\tilde{N}, 17 / 11 / 2007$, pp. $10-12$.

${ }^{29}$ Comentario de Cristianbmx2 a un video de Wachiturros, sept. 2011, disp. en http:// www.youtube.com/all_comments?v=Noy4qJseK6U [acc. 27/9/2011]. Las agresiones no son sólo virtuales: el ser un "negro de mierda" ha sido motivo de violencia policial; http://www. pagina12.com.ar/diario/sociedad/3-41404-2004-09-23.html.

${ }^{30}$ Entrevistado en Jane L. Florine, "Carlos Jimenez: Reflecting the Power of the People in Argentine Cuarteto Music": Popular Music and Society 23:3 (1998), pp. 61-113. 
junto reconocible por su fenotipo, sino más bien como un peculiar modo de referir a la posición de clase de los más pobres y los culturalmente plebeyos. En Argentina, así como el insulto racista refiere más a la posición de clase que al color de la piel, alguien perfectamente blanco puede considerarse a sí mismo un "negro". La identidad "negra" emergente no se relaciona - al menos explícitamente - con ningún sentido diaspórico que remita a un origen africano (con excepción, claro está, de los pequeños grupos que se reivindican afroargentinos). Tampoco remite a un ethnos amerindio específico, aunque pueda tener un vago sentido de mestizaje. Aparece más bien como una marca étnica en lo que es fundamentalmente una identidad de clase, antes que una identidad propiamente étnica. El propio Pablo Lescano lo explicó de este modo en un documental de 2010:

\begin{abstract}
"Nosotros decimos 'las palmas de todos los negros arriba' pero no tiene que ver con una cuestión de piel, de ser de tez oscura. Sino significa que acá le llaman negros a la clase baja. La clase baja que vive en los barrios, les dicen negros. Aunque la gente que vive en esos lugares se siente orgullosa de ser lo que es." ${ }^{31}$
\end{abstract}

La investigación etnográfica entre el público cuartetero mostró lo mismo: las alusiones a lo "negro" apuntan más a características sociales, culturales, estéticas y morales de las personas, que al color de su piel. ${ }^{32}$ Resulta interesante que aparezcan referencias positivas al "cabecita negra/negro cabeza", que evocan la manera despectiva con la que fueron motejados los seguidores de Perón en los años cuarenta. Sin embargo, no deja de llamar la atención que la identidad peronista no esté puesta en juego, al menos de manera explícita, como parte de las construcciones identitarias que venimos reseñando. Como si tratara de evocar débilmente un clivaje social del pasado, pero sin la contraparte política que en algún momento asumió.

A título de hipótesis, podría proponerse que la función de la referencia a lo negro, entonces, no es la de reivindicar la pertenencia a una "raza" o un ethnos concreto (amerindio, mestizo o afroargentino), sino la de hacer visible metonímicamente la diversidad humana que compone lo popular. Una de las figuras de la retórica más comunes, la metonimia opera, entre otras

31 “Argentine, le plus beau pays du monde...", film documental realizado por David Gormezano, Paris, 2010. Véase http://argentina.arte.tv/index_fr.html\#/pablo-lescano.

${ }^{32}$ Blazquez, "Negros de alma" (nota 19). Sobre la identidad de negro cumbiero véase Fabián Flores/Adrián Outeda, "100\% negro cumbiero. Una aproximación al proceso de construcción de las identidades entre los jóvenes urbano marginales", ponencia presentada en el 3er Congreso Virtual de Antropología y Arqueología, Ciberespacio, 2002. Disp. en http:// www.escolares.com.ar/etica-y-ciudadania/100-negro-cumbiero-una-aproximacion-al-procesode-construccion-de-las-identidades-entre-los-jovenes-urbano-marginales.html [acc. 27/9/2011]. 
maneras, aludiendo a la parte para referir al todo. En este caso, "el negro" funciona como significante englobador para la totalidad de las clases populares, cualesquiera sean sus colores. En los usos racistas propios de los discursos dominantes, esta metonimia se utiliza para transferir sobre la totalidad del bajo pueblo los estigmas asociados originalmente sólo a los de origen africano. Retomada por los sectores populares sin su carga racista, la parte está allí para referir a un todo muy diferente. El todo al que apuntan es el bajo pueblo con su diversidad de colores reconocida y aceptada, antes que negada. Una de sus partes - las personas de piel oscura - toma el lugar del todo para hacer visible que ese todo no es, como se presupone, blanco o incoloro. Al mismo tiempo, la metonimia alude también a la situación de subalternidad, asociada a los sentidos de exclusión o asimetría de poder que la palabra "negro" evoca (en Argentina, por ejemplo, como víctima del patrón "negrero" o simplemente del desprecio racista). ${ }^{33}$ De alguna manera, la operación metonímica apunta a un todo unificado, diverso pero sin oposiciones étnicas, compuesto por iguales. Es decir, un todo que sólo existe como en la letra de la murga de Palermo o la de Malón - como un deseo proyectado al futuro. ${ }^{34}$

\section{La crisis de 2001 y la politización del color}

El contexto de renegociaciones y luchas por la definición del ethnos nacional que se abrió con la crisis de la economía y los cambios en el papel del Estado, se radicalizó como resultado de la rebelión de 2001. Las impugnaciones que recibió el orden político y económico imperante fueron de una profundidad tal, que sencillamente se volvió imposible restaurarlo sin, al menos, algunos cambios. Las fluctuaciones y novedades en el escenario político y económico que trajo el kirchnerismo a partir de 2003 son incomprensibles sin tener en cuenta la profunda crisis de legitimidad que afloró en 2001, que obligó al Estado a explorar caminos inesperados en su intento por cerrarla. Como sostuve en otra parte, los discursos de campaña de Néstor Kirchner, tanto como los que sostuvo durante el resto de su gobierno, invitaban a regresar a un "país normal" caracterizado, entre otras cosas, por una pujante y progresista "clase media" descrita como la mejor herencia

${ }^{33}$ Para un ejemplo de la referencia a lo africano como excusa para discutir cualquier asimetría de poder, véase "Un continente que sirve como metáfora": Página 12, 12/6/2011.

${ }^{34}$ Rita Segato ha llamado la atención sobre el lugar fundamental del futuro deseado en la constitución de la raza, "subyacencia de un vector histórico y pulsante en cuanto pueblo"; Rita Segato, "Los cauces profundos de la raza latinoamericana: una relectura del mestizaje": Crítica y Emancipación 3 (2010), pp. 11-44. 
que los inmigrantes europeos habían dejado en el país. La idea de la Argentina blanca y europea no aparecía cuestionada sino más bien reforzada. ${ }^{35}$ Pero el discurso kirchnerista cambió abruptamente en este sentido en 2008, dando lugar a la primera utilización de envergadura del clivaje blancosnegros con fines políticos en la historia reciente de la Argentina.

En marzo de 2008, las principales entidades patronales del campo iniciaron un lock out exigiendo una reducción en las retenciones a las exportaciones (un impuesto que se había restablecido en 2002, en lo que fue uno de los efectos más inmediatos de la rebelión sobre las políticas económicas). El 25 de marzo cientos de personas opuestas al gobierno de Cristina Kirchner, ligadas al campo y/o de origen social más bien acomodado, salieron a las calles en varias ciudades en apoyo a los empresarios rurales. Los medios de comunicación lo describieron como un nuevo "cacerolazo" protagonizado por la "clase media" o simplemente por "la gente". En esa manifestación y en las varias que le siguieron abundaron los insultos racistas contra "los negros" que apoyaban al gobierno. ${ }^{36}$ Como para que quedara claro que sus cortes de ruta no eran iguales a los de los piqueteros, los empresarios rurales eligieron presentarse como "los gringos" (una sutil manera de dejar en claro que no se trataba de acciones como las de "los negros"). La irrupción del reclamo llevó a algunos periodistas que simpatizaban con la protesta a realizar fabulosas afirmaciones sobre un "nuevo 17 de octubre", esta vez protagonizado no por lo cabecitas negras peronistas sino por "gringos", que prometía restaurar el orden nacional. ${ }^{37}$

A medida que el conflicto se fue profundizando, entre algunos partidarios del gobierno se coló por primera vez un intento de apelar explícitamente a "los negros" con fines políticos y en oposición a los "blancos". Respondiendo una entrevista radial de fines de marzo en la que hubo alusiones al color de su piel, el piquetero oficialista Luis D’Elía retomó los insultos en sentido positivo y se presentó como vocero de los "negros" en lucha contra la "oligarquía" y contra el "país blanco". En intervenciones sucesivas sostuvo militantemente su "odio a los blancos", y poco después produjo

${ }^{35}$ Ezequiel Adamovsky, Historia de la clase media argentina (Buenos Aires 2009), pp. $470-472$.

${ }^{36}$ Véase Clarín, 26 y 27/3/2008 y 3/7/2008; Página 12, 23, 26, 27 y 30/3/2008 y supl. Rosario 12 de Página 12, 26/3/2008. El propio vicepresidente (hoy presidente) de la Sociedad Rural, Hugo Biolcatti, tuvo expresiones racistas; Página 12, 23/3/2008, p. 7.

${ }^{37}$ Referencias a "gringos" en "La red de 'gringos' autoconvocados": Crítica de la Argentina, 31/3/2008; Perfil, 26/3/2008; Página 12, 3/4/2008. Las referencias al 17 de octubre chacarero en "Para algunos analistas fue 'otro 17 de octubre"": La Nación, 26/5/2008; Carlos Pagni, "El 17 de Octubre de Alfredo De Angeli": La Nación, 14/6/2008; Alfredo Leuco, "Cabecitas y paisanos": Perfil, 7/6/2008. 
un texto programático en el que criticaba el "progresismo blanco" (es decir, el que no está verdaderamente compenetrado con las clases bajas). ${ }^{38}$ En ocasión del armado de las listas de candidatos para competir en las elecciones de 2009, exigió públicamente al gobierno: "No queremos listas 'blancas' y marketineras, queremos pueblo, queremos morochos que nos representen" (el acto en el que formuló la exigencia fue musicalizado con la "Cumbia negra", del grupo Los Palmeras). ${ }^{39}$ Los foros de lectores de los diarios y blogs opositores estallaron de insultos racistas comentando la noticia. Así, como los enemigos del gobierno utilizaron la descalificación racista de los "negros" como parte de su arsenal, durante el largo conflicto de 2008 también los que defendían la postura de Cristina Kirchner adoptaron la oposición "negros vs blancos" para leer la situación, tanto en intervenciones en los foros de lectores como en la prensa oficialista. ${ }^{40}$ El propio Néstor Kirchner coqueteó brevemente con ella en su conferencia de prensa del 17 de junio, cuando se quejó por la doble vara en el modo en que los medios de comunicación juzgaban los reclamos, según fueran protagonizados por "blancos" o por "morochos". ${ }^{41} \mathrm{Al}$ menos en una ocasión, con posterioridad, el tema de la discriminación de la clase media a los "morochos" apareció fugazmente en un discurso de Cristina Kirchner, lo que motivó reacciones indignadas en la prensa opositora y en los foros de lectores. ${ }^{42}$

Por cierto, la autoidentificación positiva de los peronistas como representantes de los "negros" no era nueva: aunque ni Perón ni la máxima dirigencia del partido solían expresarse en esos términos, la idea estaba presente en algunos intelectuales y en la militancia, al menos desde la época de la Resistencia peronista. El propio Néstor Kirchner, cuando era un joven y desconocido aspirante a la intendencia de Río Gallegos en 1983, se presentó como representante de "los negritos y los grasitas" en un discurso interrumpido por sus seguidores con el cántico "Somos los negros/ somos los grasitas/ somos la gente/ que vino por Evita". ${ }^{43}$ Sin embargo, incómodas

${ }^{38}$ Las expresiones de D’Elía en Clarín, 28/3/2008 y Luis D’Elía, “¿Progresismo blanco o nacionalismo popular?": Perfil.com, 21/8/2008. http://www.perfil.com/contenidos/2008/ 08/21/noticia_0029.html.

39 "D’Elía no quiere listas 'blancas' y pidió candidatos 'más morochos": Clarín, 8/5/2009; "Queremos morochos en las listas": Página 12, 8/5/2009.

${ }^{40}$ Véanse las intervenciones de Horacio Verbitsky y José Pablo Feinman en Página 12, 30/3/2008, pp. 4 y 40.

${ }^{41}$ Transmisión en vivo del canal TN, registrada por el autor.

${ }^{42}$ Véase "Reapareció Kirchner y Cristina dijo que la clase media no entiende su política": Clarín.com, 14/9/2010. http://www.clarin.com/politica/operacion-Kirchnersuspende-acto-Lanus_0_335366660.html.

${ }^{43}$ Discurso de Néstor Kirchner en Río Gallegos, 1983. Disp. en www.youtube.com/ watch?v=siuGYpy-G3A [acc. 29/5/2011]. 
para un peronismo que buscaba "modernizarse", ese tipo de exhibiciones de orgullo plebeyo se habían vuelto más bien raras a partir de mediados de los años ochenta. En este sentido, la rebelión de 2001 y especialmente el cambio en la retórica oficial a partir de 2008 multiplicaron las oportunidades para que "lo negro/morocho" apareciera públicamente como un valor político. Esta inversión del estigma asociado al ser un negro ya no fue exclusivamente vicaria - es decir, ejercida por políticos o intelectuales de tez perfectamente blanca, como Kirchner - sino que fue hecha propia por referentes kirchneristas de procedencia plebeya y pieles amarronadas. Entre 2009 y 2011, al caso de D'Elía se sumaron al menos otros tres de resonancia pública. El Secretario General de la CGT, Hugo Moyano - blanco habitual de agresiones racistas y de quien se reportó que ya en 2005 bromeaba en privado sobre su aspecto de "negro feo" - recibió con humor la bandera con la que aparecieron los afiliados a su sindicato en el masivo acto del $1^{\circ}$ de Mayo de 2009, que decía "Con el negro feo, no tenemos miedo" (acto que también fue descrito por la prensa oficialista como una demostración de fuerza de los "morochos"). ${ }^{44}$ En la no menos masiva manifestación de apoyo a la reelección de Cristina Kirchner que organizó la CGT en abril de 2011, se leyó una carta de exaltación de la figura de Moyano, escrita por una delegada gremial, que entre otros conceptos decía:

"Es morocho. Hace un tiempo pinta canas. Las canas no le aclararon la piel. Ahora es un morocho con canas. Lleva su verdad morocha como tatuaje. Esa verdad le tiñe la piel [...] Es morocho y sabe que cada día los blanquitos le miden la sangre, le toman examen, ponen a prueba su 'civilidad' [...] A la hora de reconocernos trabajadores todos quisiéramos ser camioneros y tener un morocho como vos para disputarle poder a nuestros patrones. ${ }^{45}$

Poco antes, en un acto público junto a otros dirigentes, a propósito del próximo cierre de listas para las elecciones generales, Moyano había presionado al gobierno para que más candidaturas quedaran en manos de sindicalistas. En esa ocasión se quejó de que "hay muchos que se apoderaron del partido y quieren que los negritos acompañemos las marchas y votemos, pero al momento de hacer las listas nos dejan afuera" ${ }^{46}$ Ya enfrentado abiertamente con el kirchnerismo en diciembre de 2011, se quejó del gobierno en

44 "Negro feo": Página 12, 21/2/2005; "Un acto masivo para consolidar el poder en la CGT y en el peronismo", Clarín, 2/5/2009; J. M. Pasquini Durán, "Morochos": Página 12, 2/5/2009; Mario Wainfeld, “Avanti morochos": Página 12, 3/5/2009.

45 "Es morocho y los blancos le miden la sangre": Clarín, 30/4/11.

46 "Moyano: "No puede ser que los negritos nos quedemos fuera de las listas": Infobae. com, 23/3/2011, http://www.infobae.com/notas/571480-Moyano-No-puede-ser-que-losnegritos-nos-quedemos-fuera-de-las-listas.html. 
términos similares: "Por ahí no les cae bien que un negro laburante de pelos duros, se les de por opinar políticamente." ${ }^{47}$

Por su parte la dirigente jujeña de los desocupados Milagro Sala -quien es también una referente de la lucha de los pueblos originarios - se defendió de ataques de la prensa en 2011 con declaraciones públicas del estilo: "Me investigan porque soy una negra de mierda." ${ }^{48}$ Por sus rasgos indígenas, Sala es blanco crónico de insultos de contenido racista. Aunque con menos impacto público, también el dirigente villero de base Alejandro Salvatierra se defendió de modo similar luego una ocupación de tierras en 2010, que desató una catarata de ataques racistas y xenófobos ${ }^{49}$ Por lo demás, en la militancia kirchnerista se multiplicó recientemente la utilización política de la cuestión de las diferencias de color, desde un manifiesto de movimientos sociales que piden que el Estado "se pinte de cabecita negra", hasta la canción compuesta para celebrar la figura de Néstor Kirchner luego de su muerte, en la que se lo pinta como representante de "un enjambre de morochos". ${ }^{50}$ En algunos de sus actos, los jóvenes kirchneristas suelen corear "Somos los negros/ somos los grasas/ pero gorilas no" (un canto muy parecido al que identificamos entre el público rockero). ${ }^{51}$ En 2011 incluso formaron una agrupación juvenil que eligió "Negros de Mierda" como nombre oficial. ${ }^{52}$ Como parte de la ceremonia de asunción de su segundo mandato, el 10 de diciembre de 2011, Cristina Kirchner fue recibida en la Plaza de Mayo con la canción "Avanti morocha", del cantante Ivan Noble. ${ }^{53}$

47 Discurso de Hugo Moyano el 15/12/2011, disp. en http://tn.com.ar/politica/00076206/ en-medio-de-criticas-al-gobierno-moyano-ensaya-una-demostracion-de-fuerza-en-hurac [acc. 16/12/2011].

48 "Milagro Sala defendió su visita a Punta del Este": Infobae.com, 28/1/2011, http:// www.infobae.com/notas/558744-Milagro-Sala-defendio-su-visita-a-Punta-del-Este-Por-quelos-collas-no-pueden-ir-al-Conrad.html; "Milagros Sala toma distancia de Hebe y se queja: 'Me investigan porque soy una negra de mierda": Clarín online, 19/6/2011, http://www. clarin.com/politica/Milagros_Sala-Hebe_de_Bonafini-Sergio_Schoklender_0_502150087.html.

49 "Caída y resurrección: de la cárcel a Perón (Entrevista a Alejandro Salvatierra)": Miradas al Sur, 19/12/2010.

50 "Declaración de Tucumán", 9 de julio de 2010; Horacio Bouchoux: Nunca Menos. Canción homenaje a Néstor Kirchner, 2011, disp. en www.youtube.com/watch?v= cfjeTz1LEAA [acc. 15/2/2011]. Peronistas no kirchneristas también utilizaron referencias a lo negro con fines políticos, como el chaqueño Jacinto Sampayo, quien se presentaba como "negro 100\%" en sus pintadas callejeras de 2010 en la ciudad de Resistencia.

${ }^{51}$ Véase http://www.perfil.com/contenidos/2009/04/29/noticia_0036.html [acc. 9/10/2011].

${ }^{52}$ Véase http://www.pjdigital.org/2011/04/05/pj-digital-en-el-lanzamiento-de-la-sedenacional-de-los-negros-de-mierda/ [acc. 9/10/2011].

${ }^{53}$ Véase Página 12,11/12/2011, p. 6. Debe tenerse en cuenta que "morocho" es un término ambiguo: puede referir a la tez oscura pero también al color de pelo negro (sea o no acompañado de una piel amarronada). 
Las utilizaciones políticas de lo negro tienen características similares a las que analizamos para el caso de la música popular. Tampoco aquí refieren primariamente a una "raza", a un sentido diaspórico (afro), o a cualquier otro grupo étnico particular, aunque sí tienen un vago sentido de mestizaje. Alejandro Frigerio lo ha mostrado en el análisis del discurso de D'Elía. Aunque el piquetero sabe por relatos familiares que una de sus bis o tatarabuelas era negra (afro), no se considera a sí mismo un afrodescendiente. De hecho, prefiere definirse como descendiente de inmigrantes europeos. Sin embargo, como vimos, sí se considera un "negro". Su definición, tal como lo explicó en un evento organizado por entidades de afroargentinos en noviembre de 2009, es principalmente socio-política:

“[E]l problema de la negritud hoy es un problema cultural pero también es social, político, económico, es un problema tremendo, es quizás uno de los problemas más serios que tenemos en nuestra sociedad. Porque en realidad negro no es solamente el negro, negro es el pobre en nuestro país. [...] Lo negro y lo blanco no son problemas raciales solamente, son problemas políticos, culturales, sociales muy profundos. Esta compañera que está acá a mi lado [nota de AF: fenotípicamente blanca] es una negra ¿estamos? Pelé es blanco, ¿por qué? Porque ha sido un forro del imperio toda su vida, entonces ese va a ser recordado en la memoria histórica como blanco. [...] Detrás de cualquier asimetría social, política, económica y cultural, está este tema que es la concepción racista y xenofóbica de mierda de las elites dominantes de nuestro país." 54

D'Elía prefirió sostener allí que la negritud y el racismo no eran solamente una cuestión de diferencias biológicas o de fenotipo, sino principalmente sociales. Negro no es sólo el negro (de piel), sino el pobre en general, sin importar el color de su tez. Pero el negro en particular tampoco es, para D’Elía, el negro afro. Según explicó en esa ocasión, retomando la errónea narrativa oficial, los afroargentinos "desaparecieron" por causa de las guerras y epidemias del siglo XIX. Pero si los negros (afro) no tienen una presencia relevante en la Argentina, sostuvo, existe sin embargo un "lugar simbólico del negro": "Yo siento que a las corrientes migratorias del interior de la Argentina, cobrizas, mezclada de indio con español, se les dio el lugar de los negros, heredamos el lugar que habían tenido los negros." ${ }^{55}$ D'Elía se sitúa a sí mismo en un lugar ambivalente respecto de esta herencia mestiza: si por una parte se incluye en ella ("heredamos"), por la otra elige presentarse como descendiente de europeos. Puede que en su caso la pertenencia

${ }^{54}$ Alejandro Frigerio, “Luis D’Elía y los negros: identificaciones raciales y de clase en sectores populares": Claroscuro 8 (2010), pp. 13-43.

${ }^{55}$ Ibidem. 
mestiza sea puramente política, es decir, como parte del mismo grupo oprimido, más que étnica. En cualquier caso, el significado de ser un "negro" para él es fundamentalmente social, con un vago sentido étnico referido al mestizaje con los indios, antes que con los afroargentinos. Un negro en el sentido "simbólico" puede o no ser un negro en el sentido étnico (sea afro o mestizo).

Cierto, como señala Frigerio, el uso militante de la categoría de "negro", sobre todo cuando se la opone a los "blancos", aunque no es racializado, es potencialmente racializable. ${ }^{56}$ Pero a menos que este peligro se actualice, la referencia a lo negro funciona también en el discurso de D'Elía, como en el de la cumbia villera o parte de la movida cuartetera, como una marca étnica en lo que es fundamentalmente una identidad de clase y no como una identidad propiamente étnica. La función metonímica que he descrito en el apartado anterior se vuelve aquí especialmente clara: si negro "no es solamente el negro" sino el pobre en general, a éste se lo puede nombrar como si fuera aquél, porque el negro (de piel) forma parte del mundo de la pobreza y porque los pobres son, indistintamente, objeto del racismo de las clases dominantes. En el notable razonamiento de D'Elía, por un primer deslizamiento de sentidos el mestizo ocupa el "lugar simbólico" del afro; en un segundo desplazamiento, es el pobre el que ocupa el lugar de ese "negro" ya desprovisto de un origen étnico específico.

\section{¿El Bicentenario como intento de sutura?}

En el marco de estas disputas por la redefinición del ethnos nacional, algunas políticas del Estado buscaron modos de lidiar con las impugnaciones que venía sufriendo la imagen del país blanco y europeo. En la comunicación audiovisual se notó con especial claridad. En el video del canal estatal que acompañaba la transmisión cotidiana del Himno nacional a comienzos del nuevo siglo, ya se notaba un intento por ponerse a tono con los discursos del multiculturalismo. Las imágenes de lo nacional incluían a pueblos originarios, personas de aspecto afro, oriental, de varias religiones, etc., aunque todo en un marco en el que la predominancia de lo católico-europeo, de todos modos, seguía siendo reconocible. Estereotipadas y sin ninguna jerarquía entre ellas, la impugnación que podían significar las "minorías" quedaba neutralizada. ${ }^{57}$ Por comparación, la comunicación audiovisual

56 Ibidem.

57 Disp. en http://www.youtube.com/watch?v=UFaMdjEDydY\&feature=related [acc. 28/9/2011]. 
en la etapa kirchnerista -especialmente luego de 2008 - adoptó una estrategia más rupturista. Tanto en las varias versiones del Himno nacional que el canal público patrocinó, como en otras campañas publicitarias, la presencia de personas de fenotipos mestizos no estereotipadas como minorías se volvió más visible, al punto de convertirse, por momentos, en la representación principal de lo argentino. ${ }^{58}$

Las celebraciones oficiales por el Bicentenario, el 25 de mayo de 2010, significaron en este sentido un cambio drástico respecto de las narrativas oficiales de la nación que el Estado patrocinó en el pasado. La parte central del festejo fue el desfile de 19 carrozas alegóricas por las calles porteñas, cada una de las cuales representaba un momento significativo de la historia nacional. El armado del desfile fue encargado al director de teatro vanguardista Diqui James, pero las máximas autoridades - incluyendo a la propia Cristina Kirchner - participaron en el diseño del contenido temático y conceptual. La secuencia histórica buscó deliberadamente atacar la narración de la nación blanca y europea. El desfile estaba encabezado por una alegoría de la nación, encarnada en la figura de una joven vestida de celeste y blanco que hacía una coreografía suspendida de una grúa en altura, sobre la multitud. En el casting para seleccionar a las actrices se buscó ex profeso que fueran de rasgos mestizados. ${ }^{59}$ Las siguientes tres carrozas representaban la presencia de los pueblos originarios antes de la conquista española. Los cuadros representativos de las luchas por la independencia - como el del cruce de los Andes o el éxodo jujeño - abundaban en actores afroargentinos y de rasgos y vestimentas indígenas. La escenificación del aporte inmigratorio de fines del siglo XIX fue muy singular, por el lugar que ocupa en las narrativas oficiales de la nación. Una gran carroza con forma de barco, seguida por un grupo de actores caracterizados como inmigrantes europeos, representaron el aporte de ese origen. Pero inmediatamente después, como para contrabalancear esa presencia - y alterando el orden cronológico del relato, ya que su arribo al país fue posterior -, marcharon una colorida y muy nutrida delegación de inmigrantes bolivianos (desplegando wiphalas, la bandera indígena multicolor) y luego otra de chinos, en ambos casos ataviados con sus ropas tradicionales y otros signos de su procedencia. ${ }^{60}$ Otros aspectos del festejo oficial apuntaron en un sentido similar: previo al día de cierre, un "desfile de las colectividades" mostró idéntica diver-

${ }^{58}$ Himno del canal 7 de 2008, disp. en http://www.youtube.com/watch?v=MAbQp MkKH6g; spot de difusión del programa Conectar igualdad, disp. en http://www.youtube. com/watch?v=M4R3RhdwLOk [acc. 28/9/2011].

59 “ADN wichi y diaguita en nuestras Patria-voladoras": Miradas al Sur, 30/5/2010, p. 13. Por una dificultad técnica, esa carroza inicial salió en segundo lugar.

${ }^{60}$ Disp. en http://www.tvpublica.com.ar/tvpublica/articulo?id=2730 [acc. 28/9/2011]. 
sidad y presencia de no-europeos. Entre las instalaciones diseñadas por diversos artistas en la avenida 9 de Julio - sitio central de encuentro del público - se contó el "Antimonumento del Bicentenario", del Grupo de Arte Callejero, emplazado frente al obelisco, que consistía en una serie de pantallas por las que pasaban frases y consignas. Entre ellas, una llamaba particularmente la atención: luego de referir a la revolución haitiana como la primera de las independencias latinoamericanas, un cartel repetía en letras mayúsculas: "SOMOS NEGROS/ SOMOS NEGROS/ SOMOS NEGROS/ SOMOS NEGROS". ${ }^{61}$ Y no sólo en el festejo oficial se notó este tipo de intervenciones: en el contrafestejo "El Otro Bicentenario" - un acampe frente al Congreso organizado por movimientos sociales en simultáneo a las celebraciones recién reseñadas -, la presencia de pueblos originarios, asociaciones de afroargentinos e inmigrantes de países limítrofes fue central. ${ }^{62} \mathrm{El}$ mito de la nación blanca fue uno de los temas que se abordó en las mesas de discusión, en las que varias voces denunciaron las celebraciones oficiales que se estaban llevando a cabo en ese mismo momento como un intento de reconocimiento e integración de lo no-blanco puramente superficial y oportunista. Su carácter inauténtico, según estas voces, obedecía a que el gobierno no se proponía cuestionar las bases económicas de la opresión de la población que no responde al estereotipo del argentino, bases que algunos conceptualizaron como "colonialistas" y otros simplemente como "capitalistas". ${ }^{63}$

En efecto, tanto en las manifestaciones culturales y políticas de negritud que analizamos, como en los intentos estatales de hacerles un lugar, se distinguen profundas luchas por la redefinición del ethnos nacional. Pero si todos ellos comparten el cuestionamiento de su carácter exclusivamente blanco-europeo, no está claro hasta dónde llegan los límites de la crítica. Las celebraciones del Bicentenario mostraron que aquél cuestionamiento, que de manera implícita o explícita se venía haciendo notar desde los años ochenta, había hecho mella incluso en los discursos oficiales. El mito de la nación blanca está sin dudas herido de muerte y nada permite suponer que pueda recuperar la solidez que supo tener. No está claro, sin embargo, qué narrativa nacional y qué imagen de Pueblo vayan a reemplazarlo. Para algunas voces, la celebración del Bicentenario significó "el triunfo de la patria

${ }^{61}$ Disp. en http://www.youtube.com/user/grupodeartecallejero\#p/a/u/0/0vpKKaVj13k [acc. 28/9/2011].

${ }^{62}$ Algunas fotos disp. en http://www.panuelosenrebeldia.com.ar/content/view/947/131/ [acc. 28/9/2011].

${ }^{63}$ Una síntesis de los debates en http://www.panuelosenrebeldia.com.ar/content/ view/948/215/ [acc. 28/9/2011]. 
mestiza" ${ }^{64}$ Para otras, por el contrario, se trató apenas de una puesta en escena sin cambios sustantivos por detrás.

Acaso sea muy temprano para hacer previsiones, especialmente en un escenario político y cultural tan fluctuante como el de la Argentina actual. Pero una cosa es segura: no será fácil incorporar el desafío que significa la emergencia de la negritud en los discursos oficiales de la nación, al menos no en modo definitivo. Su presencia es difícil de neutralizar desde una simple política del multiculturalismo o de afirmación identitaria, toda vez que no se trata de la expresión de un grupo étnico particular, de una "minoría" a la que una nación más tolerante pudiera hacer un lugar en su seno. Por el contrario, como hemos argumentado en este artículo, lo negro forma parte de una identidad de clase, precisamente el tipo de diferencia para las que la política del multiculturalismo es ciega.

64 "El triunfo de la patria mestiza": Miradas al Sur, 30/5/2010, pp. 14-15. 